\title{
Determination of Camelina Oil Sterol Composition and Its Application for Authenticity Studies
}

\author{
Zala Kolenc, ${ }^{1}$ Tanja Potočnik, ${ }^{2}$ Urban Bren ${ }^{1}$ and Iztok Jože Košir ${ }^{2, *}$ \\ ${ }^{1}$ Faculty of Chemistry and Chemical Technology, University of Maribor, Smetanova ulica 17, SI-2000, Maribor, Slovenia \\ ${ }^{2}$ Slovenian Institute of Hop Research and Brewing, Cesta Žalskega tabora 2, SI-3310 Žalec, Slovenia \\ *Corresponding author: E-mail: address: iztok.kosir@ihps.si. \\ Tel.: 00386037121608
}

Received: 07-10-2020

\begin{abstract}
Camelina oil has a high sterol concentration and is rather expensive compared to other vegetable oils. Because of its higher price, it is often adulterated by the addition of other, cheaper oils. This study was performed to validate a method for sterol determination in camelina oil, enabling the detection of camelina oil adulteration. Sterol levels in camelina oil samples were determined by gas chromatography after saponification and solid phase extraction. The method was validated, and the results proved that the chosen method is specific and selective, repeatable and accurate. The quantitatively

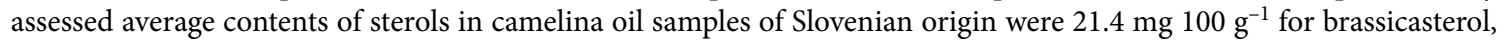
$153.6 \mathrm{mg} 100 \mathrm{~g} \mathrm{~g}^{-1}$ for campesterol, $3.9 \mathrm{mg} 100 \mathrm{~g}^{-1}$ for stigmasterol, and $447.0 \mathrm{mg} 100 \mathrm{~g}^{-1}$ for $\beta$-sitosterol. Results of camelina oil authenticity studies regarding botanical origin, performed by Principal Component Analysis (PCA) and Regularized Discriminant Analysis (RDA) enabled us to differentiate $100 \%$ camelina oils from camelina oils adulterated with $10 \%-40 \%$ added sunflower, rapeseed or soya oil.
\end{abstract}

Keywords: Camelina sativa; sterols, authenticity; botanical origin; chemometrics

\section{Introduction}

In Slovenia, the production of camelina (Camelina sativa (L.) Crantz) is maintained as an alternative oilseed crop with nutritionally important value in seed or oil form. Botanically, camelina belongs to the Brassicaceae family; it is also known as false flax, gold of pleasure, or leindotter. ${ }^{1-4}$ Recently, camelina oil has been recognized as a potential functional food because of its positive properties and its chemical composition. ${ }^{1-3}$ Camelina oil is also used for biofuel and in the cosmetics industry. ${ }^{5}$ It is an economically beneficial crop plant as it is drought tolerant, with low need for pesticide and fertilizer inputs. ${ }^{3}$ Dried camelina seeds contain $30 \%-40 \%$ oil, depending on the season of harvesting. ${ }^{5}$ Camelina oil is produced by crushing and warm-pressing the seeds, although it is very susceptible to oxidation that can lead to oil quality loss. ${ }^{3-5}$

The nutritional value of a functional food depends on its chemical composition. Camelina oil is comprised of $50 \%$ polyunsaturated fatty acids, $40 \%$ a-linolenic acid, and about $15 \%$ linoleic acid. ${ }^{1,3,4}$ Unlike other common cooking oils (such as soya, sunflower, or olive oil), camelina oil is the only oil containing oleic acid (15\%-20\%), gondoic acid $(10 \%-15 \%)$ and erucic acid (3\%). ${ }^{1,4,5}$ From the nutritional point of view, a diet with camelina oil could improve $n 6 / \mathrm{n} 3$ balance. ${ }^{1}$ Furthermore, camelina oil has self-protective antioxidative efficiency because of its high tocoferol content, $700 \mathrm{mg} \mathrm{kg}^{-1}$ on average ( $\alpha$-tocoferol, $\beta$-tocoferol, $\delta$-tocoferol) ${ }^{4,6}$ High glucosinolate content in camelina oil indicates it has more positive effects due to oxidative stability. ${ }^{6}$ Toward the oil oxidation high phenolic compounds content as chlorogenic acid in the range of $128 \mathrm{mg} \mathrm{kg}^{-1}$ could have big impact on oil quality. ${ }^{5}$

Phytosterols (plant sterols) are considered to be nutritionally important dietary lipids as unsaponifiable components of oils. Recently, phytosterols have been incorporated into functional foods. ${ }^{7}$ It has been suggested that phytosterols, in cooperation with other secondary plant metabolites, could act as cancer preventive substances. ${ }^{8}$ Chemical structure and biochemical functions of phytosterols are similar to that of cholesterol, however there are differences in synthesis, intestinal absorption and metabolic rate. Consequently, phytosterols compete with cholesterol for absorption, causing the inhibition of cholester- 
ol absorption, and the reduction of total plasma cholesterol and low-density lipid (LDL) cholesterol. ${ }^{9-11}$ The exact mechanisms involved in the inhibition of cholesterol absorption are poorly understood, although there are various theories. ${ }^{12} 30 \%-50 \%$ of cholesterol is absorbed into blood, while the phytosterols are absorbed in less than $15 \%{ }^{13} \mathrm{Re}-$ cent literature indicates that phytosterols are absorbed under the same conditions as cholesterol and other lipids. ${ }^{7}$ It has been shown that a $2 \mathrm{~g}$ daily intake of stanols and sterols reduces LDL by $10 \%$, while higher intakes of stanols and sterols does not result in bigger reduction of LDL. ${ }^{13}$ More recently, a $10 \%$ reduction of total cholesterol concentration was observed in plant sterol therapy. In addition, there was no observed difference between low-fat diets and phytosterol consumption, resulting in a lowering of cholesterol levels. ${ }^{10}$ Sitosterol, campesterol and stigmasterols are the most abundant phytosterols among more than 40 identified phytosterols in plant oils. ${ }^{13}$

Choosing the appropriate method for sterol concentration determination in vegetable oils is not an easy task, particularly where the mixture of the non-saponifiable components in food lipids results in a complex matrix. The analytical technique for sterol determination includes extraction, isolation, separation, purification, detection, and quantification steps. The combination of Solid Phase Extraction (SPE) with the use of a Gas Chromatography-Single Flame Ionization Detector (GC-FID) is considered as the most used and appropriate method for determination of sterol concentration. . $^{2,9,12,14-21}$

The aim of this study is to validate the method of sterol determination in camelina oil. Additionally, the weather effect on sterol concentration was checked. Due to its high quality, camelina oil is a target of fraudulent adulteration with cheaper products of lower quality. Therefore, in this study the validated method was used for authenticity studies in order to exclude oils adulterated with soya, sunflower, rapeseed, or other oils that belong to the same or different botanical families (Asteroidae, Fabacae, etc.) from $100 \%$ camelina oils. Apparently, these oils are widely used for this purpose, especially soya and sunflower oil. ${ }^{14,17}$ Rapeseed oil was used since it is quite common, relatively cheap, and falls into the same family as camelina (Brassicacae), ${ }^{5,14}$ unlike of sunflower (Asteroidae) and soya (Fabacae). Some reports are available where camelina oil is considered to be unique according to the chemical composition in comparison to sunflower, rapeseed and soya oil. ${ }^{1,5}$ To investigate the fraudulent adulteration of camelina oil, $10 \%-40 \%$ by weight of soya, sunflower or rapeseed oil was added. Obtained results of sterol concentration in analysis were then used as input parameters for PCA and RDA to determine if they could be used for the differentiation of pure camelina oil from other oils. PCA and RDA are multivariate statistical methods that are widely used in authenticity studies of agricultural and food products where botanical and geographical origins are investigated. ${ }^{5,22}$

\section{Experimental}

\section{1. Vegetable Oils}

Twenty-one authentic camelina seed samples, representing Camelina sativa landrace grown by local farmers in the Koroška region, Slovenia, were obtained from suppliers and farmers in three consecutive years $(2007,2008$, 2009) as described by Hrastar et al.. ${ }^{5}$ Samples were accompanied by the details of year of harvest. Seeds were cold pressed with a manual oil expeller (Piteba, The Netherlands) at room temperature. Pure sunflower, rapeseed, and soya oil was purchased at a local oil producer and used for preparing the adulterated samples. Samples were frozen at $20{ }^{\circ} \mathrm{C}$ until use.

\section{2. Chemicals}

The reagents ethanol (99.8\%), betulin (97.5\%), chloroform (99.0\%-99.4\%), methanol (99.9\%), stigmasterol (95\%), campesterol (65\%), brassicasterol (98\%), and $\beta$-sitosterol (90\%) were bought from Sigma-Aldrich. Potassium hydroxide was purchased from Riedel-de Haën. Bulk standards of individual sterols were prepared in a metha$\mathrm{nol} /$ chloroform solution $(5 \% \mathrm{v} / \mathrm{v})$. Working reference standards were prepared in the following concentrations: campesterol $\left(1 \mathrm{mg} \mathrm{mL}^{-1}\right), \beta$-sitosterol $\left(5 \mathrm{mg} \mathrm{mL}^{-1}\right)$, stigmasterol $\left(10 \mathrm{mg} \mathrm{mL}^{-1}\right)$ and brassicasterol $\left(5 \mathrm{mg} \mathrm{mL}^{-1}\right)$. All used chemicals were of p.a.

\section{3. Sample Preparation}

Sample preparation is one of the most critical steps in the analysis. Saponification was first employed, followed by solid phase extraction. ${ }^{18,19}$ For sterol determination, gas chromatography was used. Our protocol was developed based on the protocol described by Toivo et al. with minor modifications. ${ }^{18}$

We used $0.74 \mathrm{~g}$ of oil sample and $10 \mathrm{ml} 0.5 \mathrm{M} \mathrm{KOH}$ in ethanol was added. After mixing, the samples were heated to $77^{\circ} \mathrm{C}$ for 20 minutes and then cooled. Adding $10 \mathrm{ml}$ of betulin (internal standard in concentration of $0.22 \mathrm{mg} \mathrm{mL}^{-1}$ ) in chloroform was performed, and the solution was mixed well for 5 minutes. After the sludge settled, the liquid in upper portion of the container was used for further extraction. The phytosterols were then extracted by SPE, using C18-E cartridges (conditioned strata with silicon-based sorbent type), purchased from Phenomenex. The tubes volume was $6 \mathrm{~mL}$ and the sorbent mass $500 \mathrm{mg}$. For conditioning the cartridges were washed out with methanol $(5 \mathrm{~mL})$ and then with chloroform $(5 \mathrm{~mL})$. Then, in saponificated sample $1 \mathrm{~mL}$ of internal standard was added and transferred into the tube. Sterols were eluted with $15 \mathrm{~mL}$ methanol in chloroform $(5 \% \mathrm{v} / \mathrm{v})$. The extract was evaporated to dryness with vacuum evaporation at $35^{\circ} \mathrm{C}$ and the sterol fraction was re-dissolved in $1 \mathrm{~mL}$ of the same solvent (methanol in chloroform $(5 \% \mathrm{v} / \mathrm{v})$ after it. 


\section{4. Gas Chromatography}

Gas chromatography was performed with Agilent model Hewlett-Packed 6890 gas chromatograph (Hoofdoorp, The Netherlands) equipped with a flame ionization detector. An HP-5 GC column (J\&W Scientific, $30 \mathrm{~m} \times$ $0.25 \mathrm{~mm}$ i.d. with film thickness $0.25 \mu \mathrm{m}, 5 \%$ diphenil $/ 95 \%$ dimethylpolysiloxan) was used. A constant flow of helium at $1 \mathrm{ml} \mathrm{min}{ }^{-1}$ was used as a carrier gas in splitless mode. Injector temperature was $32^{\circ} \mathrm{C}$ and the temperature of the detector was set to $300^{\circ} \mathrm{C}$. The temperature program was increased from 220 to $350{ }^{\circ} \mathrm{C}$ at a rate of $3{ }^{\circ} \mathrm{C} / \mathrm{min}$, and then kept at $350^{\circ} \mathrm{C}$ an additional 6 minutes. The sample injection volume was $2 \mu \mathrm{L}$. Brassicasterol, stigmasterol, $\beta$-sitosterol, and campesterol were identified by comparing the retention times of the pure standards. For identification of brassicasterol, stigmasterol, $\beta$-sitosterol, and campesterol, the retention times were compared to external standards. Additionaly standards were added into the sample to check the matching of the increasing of individual peaks in chromatograms. The quantification was performed by using internal standard betulin.

\section{5. Method Validation}

Specificity and selectivity was checked by comparison of retention times for brassicasterol, campesterol, stigmasterol and $\beta$-sitosterol. Repeatability and reproducibility was done on two consecutive days with six measurements of the same camelina oil sample. Recovery was performed with the addition of $16.7 \mathrm{mg}$ of brassicasterol, $3.6 \mathrm{mg}$ of stigmasterol, $81.2 \mathrm{mg}$ of stigmasterol, and $16.6 \mathrm{mg}$ of $\beta$-sitosterol sepaterely for each of them and the standards were added before the extraction of sample. The linearity of the method for standards was made with the calculation of correlation coefficient over the working range of 0.058 to $0.220 \mathrm{~g} \mathrm{~L}^{-1}$ for betulin, 0.00154 to $0.15 \mathrm{~g} \mathrm{~L}^{-1}$ for brassicasterol, 0.00544 to $0.6 \mathrm{~g} \mathrm{~L}^{-1}$ for campesterol, 0.00307 to $0.3 \mathrm{~g}$ $\mathrm{L}^{-1}$ for stigmasterol, and 0.0082 to $0.8 \mathrm{~g} \mathrm{~L}^{-1}$ for $\beta$-sitosterol.

\section{6. Weather Conditions' Impact to Sterol Composition in Camelina Oil}

The sterol composition of samples from three different years was compared, considering the climate conditions of average temperature, amount of precipitation, and relative humidity during the growing season of March 1 through August 31. Climate data was obtained from the Slovenian Environmental Agency's weather forecast station Šmartno pri Slovenj Gradcu.

\section{7. Detection of Camelina Oil Adulteration}

For adulteration analyses, the mixtures of camelina oil with sunflower, rapeseed, and soya oils at levels of $10,20,30$, and $40 \%$ were prepared. Statistical analysis was performed using the SCANWIN software (Minitab Inc., USA). The applied chemometric methods were principal component analysis and regularized discriminate analysis.

\section{Results and Discussion}

\section{1. Method Validation}

At first, camelina oil samples collected from Slovenian producers were used for the method validation in the laboratory. Chromatographic peaks were identified on the basis of retention time in comparison with the standards brassicasterol, campesterol, stigmasterol, and $\beta$-sitosterol, and the internal standard betulin. Retention times were from 7.20 to 8.05 minutes for sterols and 10.63 minutes for the internal standard betulin. A random sample was used to determine the specificity and selectivity of the method, as shown in Figure 1 and Table 1. The described sample preparation enabled the complete separation of the sterols of interest from the camelina oil. The results show that the method is specific and selective since there were no overlapping peaks.

Table 1. Retention times for sterols and internal standard (betulin).

\begin{tabular}{lccc}
\hline Sterol name & $\mathbf{t}_{\mathbf{r}}$ (min) & $\begin{array}{c}\text { Linear Retention } \\
\text { Indices }\end{array}$ & Identifier \\
\hline brassicasterol & 7.218 & $2640 \mathrm{iu}$ & 1 \\
campesterol & 7.419 & $2632 \mathrm{iu}$ & 2 \\
stigmasterol & 7.806 & $2739 \mathrm{iu}$ & 3 \\
$\begin{array}{l}\beta \text {-sitosterol } \\
\text { internal standard } \\
\text { (betulin) }\end{array}$ & 8.053 & $2731 \mathrm{iu}$ & 4 \\
\hline
\end{tabular}

The validation shows the method is repeatable, reproducible, linear, and with good recovery of samples from 85.08 to $98.11 \%$, together with acceptably low standard deviation (Table 2). Repeatability of the method was tested with 12 individual determinations at the concentrations comparable with those determined in real samples. Relative standard deviations for all four sterols were between 4.9 and $7.8 \%$ (Table 2). Accuracy was tested with relatively low concentrations with the standard addition of a particular sterol into the real sample. Recoveries for all four sterols were higher than $85 \%$ (Table 2). Linearity of the method was tested at 6 different concentrations covering the range where all analysed samples were found to be. The correlation coefficient were all higher than 0.99 . For the purpose of method validation limits of detection and quantifications were not determined since all analysed sterols were present in the samples at much higher concentrations within the linear concentration range and the results for repeatability and accuracy showed satisfactory results. 


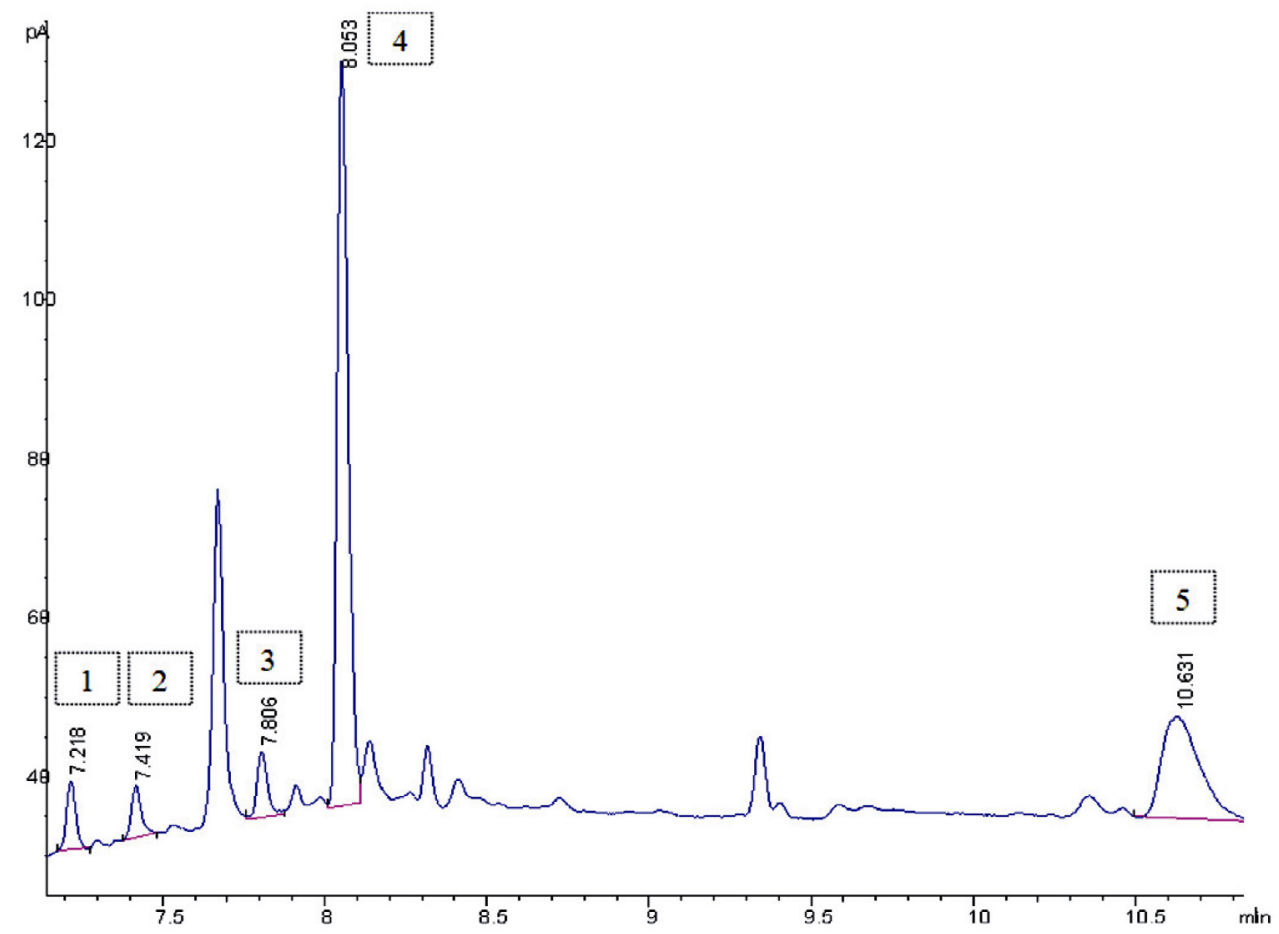

Figure 1. Gas chromatogram of camelina oil sample. Identifiers are the same as in Table 1.

Table 2. Results of the method validation parameters.

\begin{tabular}{|c|c|c|c|c|c|c|}
\hline $\begin{array}{l}\text { Sterol } \\
\text { name }\end{array}$ & $\begin{array}{c}\text { Linearity- } \\
\operatorname{range}^{\star}\left(\mathrm{mg} \mathrm{L}^{-1}\right)\end{array}$ & $\begin{array}{c}\text { Linearity - } \\
\text { equation }\end{array}$ & $\begin{array}{c}\text { Correlation } \\
\text { coeficient - } \mathbf{R}^{2}\end{array}$ & $\begin{array}{c}\mathrm{SD}^{\star \star} \\
\left(\mathrm{mg} 100 \mathrm{~g}^{-1}\right)\end{array}$ & $\begin{array}{c}\text { RSD } \\
(\%)\end{array}$ & $\begin{array}{c}\operatorname{Recover}^{\star * *} \\
(\%)\end{array}$ \\
\hline brassicasterol & $1.54-150$ & $y=1827 x+6.345$ & 0.994 & \pm 0.9 & \pm 4.9 & 85.72 \\
\hline campesterol & $5.44-600$ & $y=2588 x-19.05$ & 0.997 & \pm 11.2 & \pm 6.6 & 89.95 \\
\hline stigmasterol & $3.07-300$ & $y=2381 x-3.831$ & 0.991 & \pm 0.4 & \pm 7.8 & 85.08 \\
\hline$\beta$-sitosterol & $8.20-800$ & $y=2181 x-32.73$ & 0.996 & \pm 36.5 & \pm 6.9 & 98.11 \\
\hline
\end{tabular}

${ }^{*}$ linearity at 6 points ${ }^{* *}$ standard deviation at 12 repetitions for brassicasterol at concentration in oil $18.5 \mathrm{mg}^{*} 100 \mathrm{~g}^{-1}$, campesterol at concentration

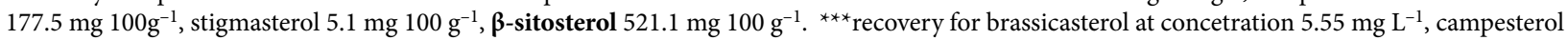
at concentration $3.34 \mathrm{mg} \mathrm{L}^{-1}$, stigmasterol at concentration $8.12 \mathrm{mg} \mathrm{L}^{-1}, \beta$-sitosterol at concentration $16.67 \mathrm{mg} \mathrm{L}^{-1}$.

\section{2. Sterol Content in Camelina Oil}

Sterols were found in 21 samples of authentic camelina oil. The results for each year of production are presented in Table 3.

The average concentration of brassicasterol in all camelina oil samples, regardless of the year of production, was $21.4 \mathrm{mg} 100 \mathrm{~g}^{-1}$, which is comparable with other research results, ${ }^{11}$ who found the same sterol in camelina oil in the concentration $27 \mathrm{mg} 100 \mathrm{~g}^{-1}$. For campesterol, we determined the concentration averaged $153.6 \mathrm{mg} 100 \mathrm{~g}^{-1}$, while in other research ${ }^{11}$ it was determined their concentration as $117 \mathrm{mg} 100 \mathrm{~g}^{-1}$. In addition, the stigmasterol

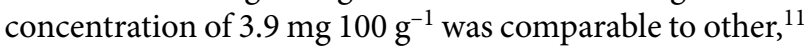

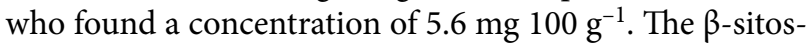
terol concentration was $447.0 \mathrm{mg} 100 \mathrm{~g}^{-1}$ in our camelina samples, while Schwartz et al. found lower ${ }^{11}$ but comparable values (300 mg $100 \mathrm{~g}^{-1}$ ).

\section{3. Sterol Content in Three Different Years of Harvest}

Detailed camelina oil samples of different harvest years were used to determine the correlation, and the effects of growth conditions, on sterol content as it was described for fatty acids and tocopherols. ${ }^{1}$ The results of the sterol content analyses in camelina oil from the harvest years 2007, 2008, and 2009 revealed small differences. There were no statistically significant differences in sterol composition in the different harvest years. This was confirmed using calculated $t$-values between different years (data not shown here). The basic data for sterol composition in three consecutive years is presented in Table 3.

In Table 4, the weather conditions during the growing seasons (usually March 1 through August $31^{2,5}$ ) are described. There were no significant differences between 
Table 3. Camelina oil samples detailed with year of oil production and sterol composition. Mean, Standard Deviation, Relative Standard Deviation, Minimum and Maximum of Camelina oil samples with regard to the year are given.

\begin{tabular}{|c|c|c|c|c|}
\hline & Brassicasterol & Campesterol & Stigmasterol & $\beta$-sitosterol \\
\hline \multicolumn{5}{|l|}{ Camelina oil samples (year 2007) } \\
\hline Mean $(\mathrm{N}=8)\left(\mathrm{mg} 100 \mathrm{~g}^{-1}\right)$ & 23.2 & 162.6 & 3.8 & 492.1 \\
\hline$\pm \mathrm{SD}$ & 5.1 & 21.5 & 1.8 & 65.1 \\
\hline$\pm \mathrm{RSD}(\%)$ & 22.1 & 13.2 & 48.5 & 13.2 \\
\hline $\min$ & 18.7 & 134.8 & 1.7 & 391.0 \\
\hline $\max$ & 34.5 & 199.4 & 6.9 & 549.7 \\
\hline \multicolumn{5}{|l|}{ Camelina oil samples (year 2008) } \\
\hline Mean $(\mathrm{N}=6)\left(\mathrm{mg} 100 \mathrm{~g}^{-1}\right)$ & 20.6 & 153.8 & 4.3 & 432.5 \\
\hline$\pm \mathrm{SD}$ & 4.3 & 20.5 & 1.5 & 59.0 \\
\hline$\pm \mathrm{RSD}(\%)$ & 21.1 & 13.4 & 35.0 & 13.6 \\
\hline $\min$ & 15.9 & 135.8 & 2.1 & 405.0 \\
\hline $\max$ & 27.7 & 187.7 & 6.6 & 552.8 \\
\hline \multicolumn{5}{|l|}{ Camelina oil samples (year 2009) } \\
\hline Mean $(\mathrm{N}=7)\left(\mathrm{mg} 100 \mathrm{~g}^{-1}\right)$ & 20.1 & 143.1 & 3.6 & 407.8 \\
\hline$\pm \mathrm{SD}$ & 3.6 & 18.9 & 1.8 & 54.3 \\
\hline$\pm \mathrm{RSD}(\%)$ & 18.0 & 13.2 & 49.1 & 13.3 \\
\hline $\min$ & 16.1 & 121.8 & 1.4 & 324.1 \\
\hline $\max$ & 26.6 & 176.4 & 5.6 & 472.5 \\
\hline 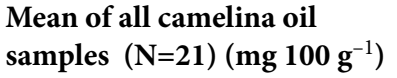 & 21.4 & 153.6 & 3.9 & 447.0 \\
\hline
\end{tabular}

Table 4. Weather conditions from March to August reported by the Slovenian Environmental Agency.

\begin{tabular}{cccc}
\hline Year & $\begin{array}{c}\text { Average } \\
\text { temperature } \\
\left({ }^{\circ} \mathbf{C}\right)\end{array}$ & $\begin{array}{c}\text { Average relative } \\
\text { humidity } \\
\mathbf{( \% )}\end{array}$ & $\begin{array}{c}\text { Total amount } \\
\text { of precipitation } \\
(\mathbf{m m})\end{array}$ \\
\hline 2007 & $14.7 \pm 5.5$ & $73.2 \pm 4.4$ & 798.4 \\
2008 & $13.9 \pm 6.2$ & $74.8 \pm 3.8$ & 746.9 \\
2009 & $14.5 \pm 5.7$ & $73.0 \pm 2.4$ & 706.5 \\
\hline
\end{tabular}

the three years. There is no connection between weather conditions and sterol content.

\section{4. Sterol Content in Other Oils}

Sunflower, rapeseed, and soya oils were also analyzed, and the sterol content of these oils is presented in Table 5 .

For sunflower oil, there were concentrations detected at $35.9 \mathrm{mg} 100 \mathrm{~g} \mathrm{~g}^{-1}, 91.1 \mathrm{mg} 100 \mathrm{~g} \mathrm{~g}^{-1}, 91.5 \mathrm{mg} 100 \mathrm{~g}^{-1}$, and $345.5 \mathrm{mg} 100 \mathrm{~g}^{-1}$, respectively for brassicasterol, campes- terol, stigmasterol and $\beta$-sitosterol. In another study were found lower concentrations of brassicasterol, campesterol and stigmasterol. ${ }^{11}$ While the obtained $\beta$-sitosterol concentration was comparable with our results. For rapeseed oil, our results for sterol concentrations were comparable to similar research. ${ }^{11,21}$ One study found brassicasterol content in rapeseed oil as $71-78 \mathrm{mg} 100 \mathrm{~g}^{-1}, 271-315 \mathrm{mg} 100$ $\mathrm{g}^{-1}$ for campesterol, 3-5 mg $100 \mathrm{~g}^{-1}$ for stigmasterol, and $376-430 \mathrm{mg} 100 \mathrm{~g}^{-1}$ for sitosterol..$^{11}$ Also, it was found that sterol composition of rapeseed oil was comparable to our results: brassicasterol $69.6 \mathrm{mg} 100 \mathrm{~g}^{-1}$, campesterol 232.5 $\mathrm{mg} 100 \mathrm{~g}^{-1}$, stigmasterol $2.4 \mathrm{mg} 100 \mathrm{~g}^{-1}$, and $\beta$-sitosterol $324.7 \mathrm{mg} 100 \mathrm{~g}^{-1} .{ }^{23}$ In soya oil, only two sterols were found: stigmasterol in average concentration of $114.7 \mathrm{mg} 100 \mathrm{~g}^{-1}$,

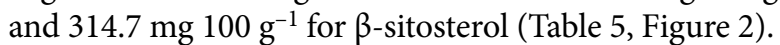

\section{5. Authenticity Studies of Camelina Oil}

For the authenticity studies, the sunflower, rapeseed and soya oils were used to adulterate camelina oil in ranges of $10,20,30$, and $40 \%$. The results of sterol determination are shown in Table 6.

Table 5. Sterol content in sunflower, rapeseed and soya oils used for adulteration.

\begin{tabular}{lcccc}
\hline Oil/sterol name & Brassicasterol & Sterol concentration $\left(\mathbf{m g ~ 1 0 0 ~ ~ ^ { - 1 } )}\right.$ & \\
Campesterol & Stigmasterol & $\boldsymbol{\beta}$-sitosterol \\
\hline Sunflower & $35.9 \pm 3.2$ & $91.1 \pm 50.2$ & $91.5 \pm 13.0$ & $345.5 \pm 142.5$ \\
Rapeseed & $10.4 \pm 5.1$ & $472.4 \pm 25.6$ & $5.5 \pm 5.7$ & $565.9 \pm 84.1$ \\
Soya & 0.0 & 0.0 & $114.7 \pm 16.7$ & $314.7 \pm 8.0$ \\
\hline
\end{tabular}



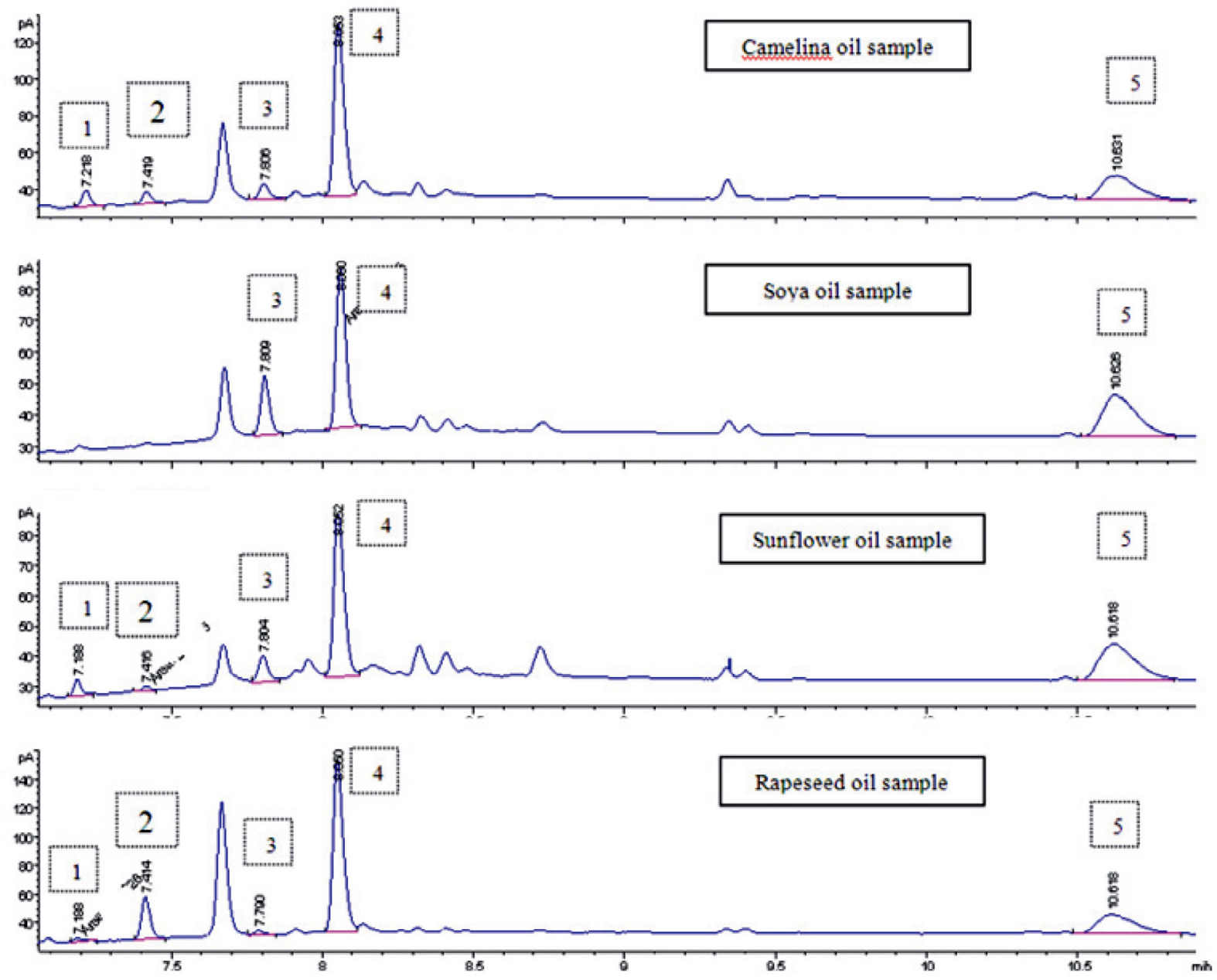

Figure 2. Comparison of camelina, soya, sunflower and rapeseed oil sample gas chromatogram: identifiers are the same as in Table 1.

Table 6. Sterol content of adulterated camelina oil $\left(\mathrm{mg} 100 \mathrm{~g}^{-1}\right)$ with sunflower, rapeseed or soya oil.

\begin{tabular}{|c|c|c|c|c|c|}
\hline Oil mixture name & $\%$ of oil adulteration & Brassicasterol & Campesterol & Stigmasterol & $\beta$-sitosterol \\
\hline \multirow{4}{*}{ Camelina+Sunflower } & $10 \%$ & 55.7 & 206.3 & 7.4 & 463.1 \\
\hline & $20 \%$ & 41.0 & 182.8 & 9.8 & 437.6 \\
\hline & $30 \%$ & 35.2 & 197.1 & 14.3 & 495.7 \\
\hline & $40 \%$ & 43.9 & 172.3 & 17.6 & 460.4 \\
\hline \multirow{4}{*}{ Camelina+Rapeseed } & $10 \%$ & 48.2 & 275.7 & 9.8 & 585.7 \\
\hline & $20 \%$ & 41.7 & 286.3 & 4.0 & 550.8 \\
\hline & $30 \%$ & 40.2 & 314.8 & 6.9 & 568.8 \\
\hline & $40 \%$ & 34.5 & 371.1 & 5.9 & 640.0 \\
\hline \multirow{4}{*}{ Camelina+Soya } & $10 \%$ & 50.7 & 277.3 & 23.1 & 648.2 \\
\hline & $20 \%$ & 45.8 & 265.7 & 28.6 & 616.2 \\
\hline & $30 \%$ & 41.1 & 251.7 & 45.7 & 569.9 \\
\hline & $40 \%$ & 34.4 & 211.6 & 49.3 & 452.4 \\
\hline
\end{tabular}

PCA (Figure 3) was applied to the data matrix formed by sterol composition in pure camelina oils, and in samples mixed with sunflower, rapeseed and soya oils. On the score plot of the first two principle components, which account for $60.6 \%$ and $22.7 \%$ of variance respectively, good visual discrimination was obtained. The first two PC account 83.3\% of total variance, while PC3 and PC4 contain 12.4 and $4.3 \%$ of variance. Results clearly indicate that the PCA analysis separated pure camelina oil samples from the adulterated ones. Moreover, three different groups of adulterat- 
ed oils were found, according to the oil used for adulteration. Comparison of the distribution taking into account also PC3 and PC4 has not resulted in a satisfactory discrimination of groups what is expectable since they are carrying low variance information of 12.4 and $4.3 \%$ only.

Table 7. Loadings values of the variables associated with principal components calculated using sterol composition data

\begin{tabular}{llrrr}
\hline Sterol name & PC1 & \multicolumn{1}{c}{ PC2 } & PC3 & \multicolumn{1}{c}{ PC4 } \\
\hline brassicasterol & -0.520 & -0.107 & 0.831 & -0.167 \\
campesterol & -0.563 & 0.315 & -0.162 & 0.747 \\
stigmasterol & -0.338 & -0.885 & -0.316 & 0.050 \\
$\beta$-sitosterol & -0.546 & 0.326 & -0.428 & -0.642 \\
\hline
\end{tabular}

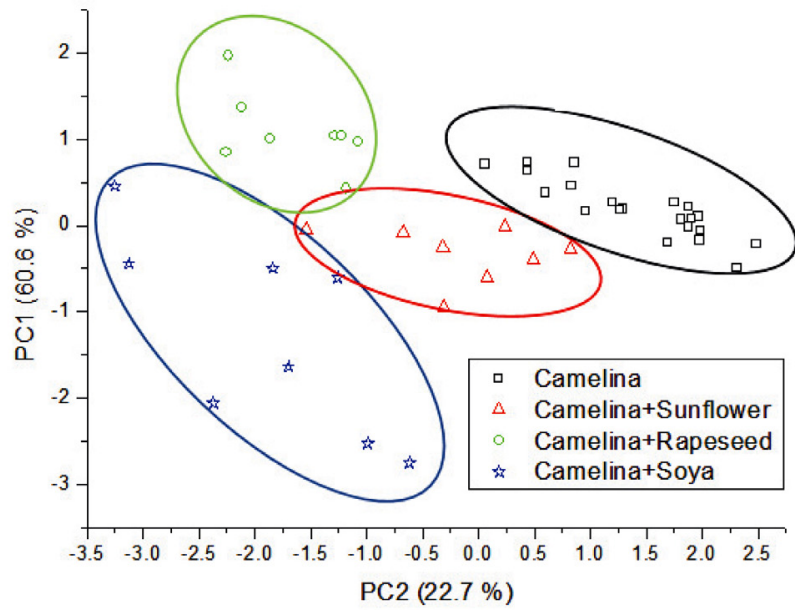

Figure 3. Projection of 21 objects of camelina oil and 4 for mixtures of camelina with sunflower oil, 4 for mixtures of camelina with rapeseed oil and 4 for mixtures of camelina with soya oil, onto the plot defined by the first and second principal components. The PCA model was calculated based on sterol composition.

\section{RDA Class Assignments}

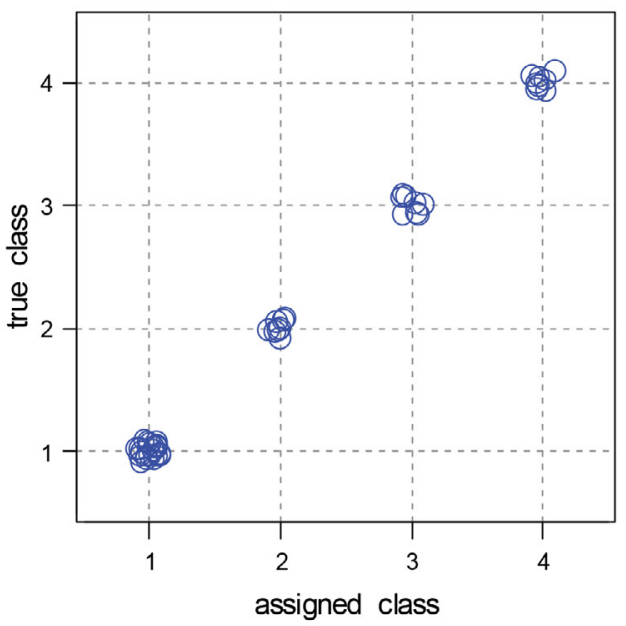

The loading values of the variables associated to the first two principal components are reported in Table 7 and shown in Figure 4. In the Table 7 and Figure 4 the contribution of the variables to the more significant principal components is shown. According to these values, pure camelina oils are described as samples with the lowest campesterol, mixtures with soya oil contain highest amount of stigmasterol, while mixtures with rapeseed oil are the most abounded by campesterol.

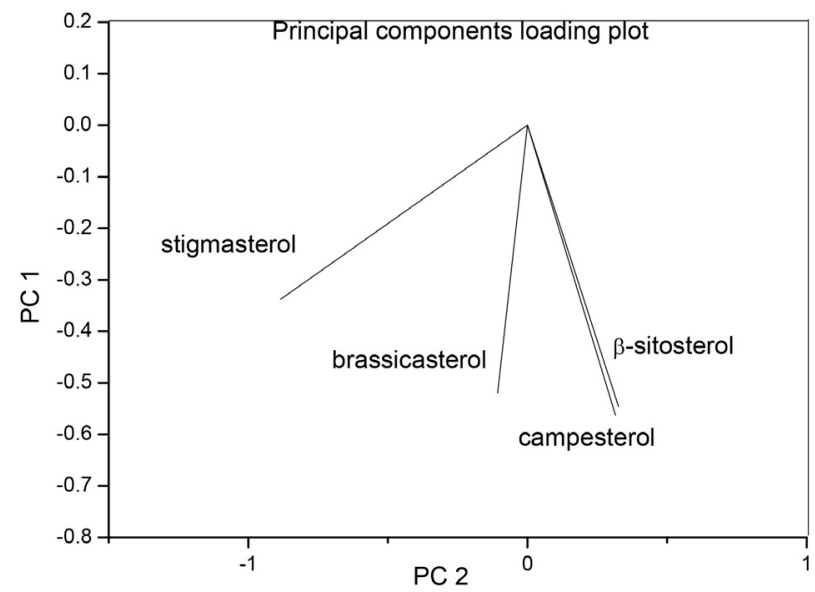

Figure 4. Principal components loading plot for PC1 and PC2 for the PCA model calculated based on sterol composition of 21 objects of camelina oil and 4 for mixtures of camelina with sunflower oil, 4 for mixtures of camelina with rapeseed oil and 4 for mixtures of camelina with soya oil.

After PCA (an example of an unsupervised chemometric method), RDA (an example of a supervised method), was used to calculate the model for discrimination of samples and to validate the constructed model. Analysis with RDA (Figure 5) resulted in the formation of

\section{RDA Xvalidated Class Assignments}

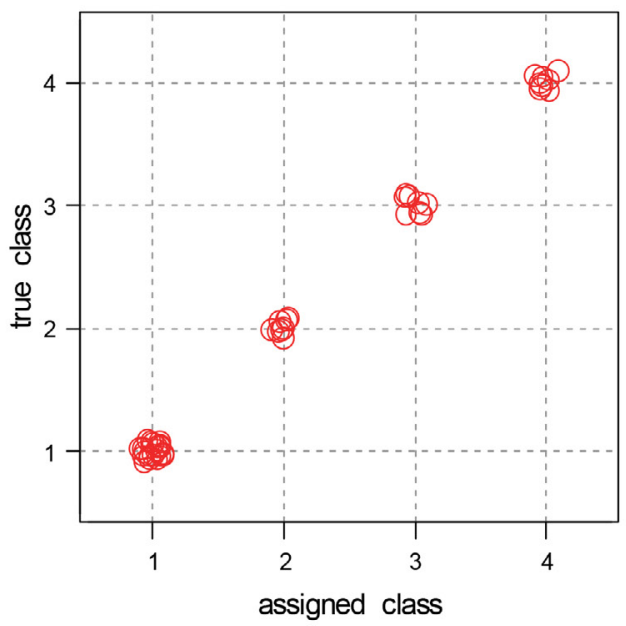

Figure 5. Classification of pure camelina oil and mixture clusters on the basis of the calculated RDA model and the results of validation model, using the cross-validation test. RDA model was calculated based on sterol composition. The RDA model was obtained based on sterol composition. 
four classes: pure camelina oil, camelina oil adulterated with sunflower oil, camelina oil adulterated with rapeseed oil, and camelina oil adulterated with soya oil. All applied samples were identified correctly according to their botanical origin, independent of the amount of oils added.

\section{Conclusions}

In conclusion, the present work proves that the method used is appropriate for sterol determination in camelina oil. This study confirms the unique sterol composition of camelina oil as a prerequisite for authenticity studies, based on sterol determination using gas chromatography. Results of camelina oil authentication verify the use of authenticity studies based on sterol composition. For further research, it is recommended that sterol determination be combined with other minor components for adulteration investigations. This method would enhance the ability to prevent fraudulent adulteration.

\section{Acknowledgements}

This work was financially supported by the Slovenian Ministry of Education, Science and Sports through programme grants F4F, Ab Free and C3330-19-952022 and Slovenian Research Agency through research programme P1-0242.

\section{References}

1. J. Zubr, B. Matthäus, Ind. Crop. Prod. 2002, 15, 155-162. DOI:10.1016/S0926-6690(01)00106-6

2. J. Zubr, Ind. Crop. Prod. 1997, 6, 113-119. DOI:10.1016/S0926-6690(96)00203-8

3. L. Fan, N. A. M Eskin, Recent Res. Devel. Lipids. 2013, 9, 125-137.

4. H. Abramovič, V. Abram, Food Technol. Biotechnol. 2005, 43, 63-70.

5. R. Hrastar, M. G. Petrišič, N. Ogrinc, I. J. Košir, J. Agric. Food Chem. 2009, 57, 579-585. DOI:10.1021/jf8028144

6. M. A. Berhow, U. Polat, J. A. Glinski, M. Glensk, S. F. Vaughn, T. Isbell, I. Ayala-Diaz, L. Marek, C. Gardner, Ind. Crop. Prod. 2013, 43, 119-125. DOI:10.1016/j.indcrop.2012.07.018

7. G. García-Llatas, M. T. Rodríguez-Estrada, Chem. Phys. Lipids. 2011, 164, 607-624.

DOI:10.1016/j.chemphyslip.2011.06.005

8. B. Cañabate-Díaz, S. Carretero, A. Fernández-Gutiérrez, A. Belmonte Vega, A. Garrido Frenich, J. L. Martínez Vidal, J. Duran Martos, Food Chem. 2007, 102, 593-598.

9. J. Toivo, K. Phillips, A. M. Lampi, V. Piironen, J. Food Comp. Anal. 2001, 14, 631-643. DOI:10.1006/jfca.2001.1019

10. M. H. Moghadasian, J. J. Frohlich, Am. J. Med. 1999, 107, 588-594. DOI:10.1016/S0002-9343(99)00285-5
11. H. Schwartz, V. Ollilainen, V. Piironen, A. M. Lampi, J. Food Comp. Anal. 2008, 21, 152-161. DOI:10.1016/j.jfca.2007.07.012

12. M. J. Lagarda, G. García-Llatas, R. Farré, J. Pharmaceut. Biomed. 2006, 41, 1486-1496. DOI:10.1016/j.jpba.2006.02.052

13. M. B. Katan, S. M. Grundy, P. Jones, M. Law, T. Miettinen, R. Paoletti, Mayo Clin Proc. 2003, 78, 965-978. DOI:10.4065/78.8.965

14. R. Aparicio, R. Aparicio-Ruíz, J. Chromatogr. A. 2000, 881, 93-104. DOI:10.1016/S0021-9673(00)00355-1

15. E. O. Aluyor, C. E. Ozigagu, O. I. Oboh, P. Aluyor, Sci. Res. Essays. 2009, 4, 191-197.

16. S. L. Abidi, J. Chromatogr. A. 2001, 935, 173-201. DOI:10.1016/S0021-9673(01)00946-3

17. K. M. Al-Ismail, A. K. Alsaed, R. Ahmad, M. Al-Dabbas, Food Chem. 2010, 121, 1255-1259.

DOI:10.1016/j.foodchem.2010.01.016

18. J. Toivo, V. Piironen, P. Kalo, P. Varo, Chromatographia. 1998, 48, 745-750. DOI:10.1007/BF02467642

19. J. Toivo, A. M. Lampi, S. Aalto, V. Piironen, Food Chem. 2000, 68, 239-245. DOI:10.1016/S0308-8146(99)00201-0

20. C. Ö. Yücel, H. Ertaş, F. N. Ertas. Turkish Journal of Agriculture - Food Science and Technology. 2017, 5(11), 1274. DOI:10.24925/turjaf.v5i11.1274-1278.1267

21. A. Gorassini, G. Verardo, R. Bortolomeazzi, Food Chem. 2019, 283, 177-182. DOI:10.1016/j.foodchem.2018.12.120

22. I. J. Košir, M. Kocjančič, N. Ogrinc, J. Kidrič, Anal. Chim. Acta. 2001, 429, 195-206.

DOI:10.1016/S0003-2670(00)01301-5

23. A. Szterk, M. Roszko, E. Sosińska, D. Derewiaka, P.P. Lewicki, J. Am Oil Chem Soc. 2010, 87, 637-645. DOI:10.1007/s11746-009-1539-4 


\section{Povzetek}

Ričkovo olje ima visoko vsebnost sterolov in je v primerjavi z drugimi rastlinskimi olji precej drago. Zaradi višje cene so zelo pogoste potvorbe ričkovega olja $\mathrm{z}$ dodatkom drugih, cenejših olj. Zgoraj opisana študija je bila izvedena za potrditev metode za določanje sterolov v ričkovem olju, ki omogoča odkrivanje potvorb ričkovega olja. Koncentracije sterolov v vzorcih ričkovega olja so bile določene s plinsko kromatografijo, pred tem pa smo opravili saponifikacijo in ekstrakcijo na trdni fazi. Metoda je bila validirana, rezultati pa so dokazali, da je izbrana metoda specifična in selektivna, ponovljiva in natančna. Kvantitativno določena povprečna vsebnost sterolov v vzorcih ričkovega olja slovenskega izvora je bila 21,4 mg $100 \mathrm{~g}^{-1}$ za brasikasterol, 153,6 mg $100 \mathrm{~g}^{-1}$ za kampesterol, 3,9 mg $100 \mathrm{~g}^{-1}$ za stigmasterol in 447,0 mg $100 \mathrm{~g}^{-1}$ za $\beta$-sitosterol. Potvorbe ričkovega olja glede na botanični izvor olja, smo opravili z analizo glavnih komponent (angl. Principal Component Analysis, PCA) in z regulatorno analizo diskriminacije (angl. Regularized Discriminant Analysis, RDA). Rezultati študije so pokazali, da lahko ločimo $100 \%$ ričkovo olja od ričkovega olja, ki je potvorjeno z $10 \%$ - $40 \%$ dodanega sončničnega, repičnega ali sojinega olja . 